\title{
İki Boyutlu Radyo-Manyetotellürik Verilerin Doğrusal Olmayan Yüzdelik Süzgeç ile Parçacık Sürüsü Optimizasyonu Kullanılarak Modellenmesi
}

\section{Two Dimensional Modeling of Radio-Magnetotelluric Data Using Particle Swarm Optimization with Non-Linear Percentile Filter}

\author{
GÖKHAN KARCIOĞLU1* \\ 1 İstanbul Üniversitesi-Cerrahpaşa, Mühendislik Fakültesi, Jeofizik Mühendisliği Bölümü, Büyükçekmece, İstanbul
}

Geliş (received): 23 Ekim (October) 2020 Kabul (accepted) : 18 Kasım (November) 2021

Öz

Jeofizik verilerin modellenmesi amacıyla uygulanan geleneksel ters çözüm yöntemlerinde, yuvarlatıcılı ve keskin sınırı modelleme için genelde türev tabanlı operatörler kullanılır. Bu yöntemler verilerin model parametrelerine göre kısmi türevlerinden oluşan Jacobian dizeyine gereksinim duyar. Buna karşın, Jacobian dizeyinin hesabı çoğu Global Optimizasyon uygulaması için gereksizdir ve en uygun model kısmen rastgeleleştirilmiş deneme yanılmalar ile belirlenir. Gerçekleştirilen deneme yanılmalar esnasında model parametrelerine çeşitli süzgeçler uygulanarak, elde edilecek modelin nitelikleri sınırlandırılabilmektedir. Bu çalışmada, doğrusal olmayan yüzdelik süzgeç kullanılarak görece verimli bir Global Optimizasyon yaklaşımı geliştirilmiştir. Yöntemin verimliliği, evrimsel bir Global Optimizasyon yöntemi olan Parçacık Sürüsü Optimizasyonu kullanılarak gösterilmiştir ve Radyo-Manyetotellürik verilerin iki boyutlu modellenmesi için uygulanmıştır. Yüzdelik süzgecin, elde edilen model parametrelerindeki yüksek frekansı değişimleri atarken yapı sınıllarını koruyabildiği gözlenmiştir. İşlecin başarısı hem yapay hem de arazi veri kümeleri üzerinde gösterilmiş ve sonuçları kıyaslanmıştır.

Anahtar Kelimeler: RMT, PSO, 2B modelleme, Yüzdelik süzgeç.

\begin{abstract}
Smooth and sharp boundary modeling methods, used in traditional inversion methods for modeling geophysical data, are generally implemented using derivative based operators. These methods depend on the Jacobian matrix, which consist of partial derivatives of data according to the model parameters. In contrary, calculation of the Jacobian matrix is not necessary in most Global Optimization applications and the optimum model is determined using partially randomized trial and errors. The properties of the models to be recovered can be constrained by applying various filters during these trial and errors. In this study, a relatively efficient Global Optimization approach is developed using a non-linear percentile filter. The efficiency of the method is demonstrated using Particle Swarm Optimization, which is an evolutional Global Optimization method, and applied for twodimensional modeling of Radio-Magnetotelluric data. In the developed algorithm, Percentile filter is observed to be filtering high frequency variations in model parameters while keeping boundaries. The ability of the developed algorithm is shown on both synthetic and field datasets, and the results are compared.
\end{abstract}

Keywords: RMT, PSO, 2D modeling, Percentile filter. 


\section{GíRiş}

Global Optimizasyon yöntemleri ile jeofizik modelleme problemlerinin çözümü genellikle, kısmen rastgeleleştirilmiş metotlarla üretilen modellerin, gözlenen ve hesaplanan veriler arasındaki farkı en küçüklemesi (minimize etmesi) ile gerçekleştirilir. Bu işlem çok sayıda düz çözüm gerektirdiğinden işlemci zamanı olarak maliyeti geleneksel ters çözüm yöntemlerine kıyasla çok daha yüksektir. Buna karşın, her bir yinelemede gerçekleştirilen düz çözüm işlemleri birbirinden bağımsız olduğu için bilgisayarların paralel işlem yapabilme kabiliyetlerinden geleneksel ters çözüm yöntemlerine göre daha verimli faydalanabilirler. Özellikle son 15 yılda, bilgisayarların artan işlemci (CPU) sayıları ile Global Optimizasyon yöntemleri çok boyutlu jeofizik problemler için daha uygulanabilir hale gelmiştir (Sen ve Stoffa, 2013). Bu nedenle, global yöntemlerin jeofizik problemlerde daha verimli uygulanabilmesi için yeni yaklaşımlar geliştirilmesi önem kazanmaktadır.

Global yöntemlerin uygulanabilirliğinin artması ile jeofizik modelleme amacıyla kullanılmalarına yönelik çalışmalar da ivmelenmiştir. Genetik Algoritmalar (GA) ve Parçacık Sürüsü Optimizasyonu (PSO), Global Optimizasyon'un evrimsel işleçler kategorisindedir ve jeofizik problemlere en çok uygulanan yöntemler arasındadırlar. Bu yöntemlerin jeofizik modellemedeki başarısı son yıllarda gerçekleştirilen çalışmalarda da kendisini göstermektedir. Montesinos vd. (2005) çalışmasında GA ile gravite verilerinin modellemesi gerçekleştirilmiştir. Moorkamp vd. (2007, 2010) çalışmalarında GA ile sismik ve elektromanyetik verilerin birleşik modellemeleri gerçekleştirmiştir. Akça ve Başokur (2010), GA ile Doğru Akım Özdirenç verilerin yapısal modellemesini gerçekleştirmiştir. Pekşen vd. (2011), PSO ile Doğal Potansiyel verileri modellemiştir. Pekşen vd. (2014) çalışmasında yine PSO ile Düşey Elektrik Sondaj verilerinin bir boyutlu anizotropik modellemesi gerçekleştirilmiştir. Attwa vd. (2014) çalışmasında, GA ile Düşey Elektrik Sondaj verileri modellenmiştir. Balkaya vd. (2014) çalışmasında, PSO ile Doğal Potansiyel anomalileri ve GA ile Düşey Elektrik Sondaj verileri bir boyutlu modellenmiştir. Akça vd. (2014) çalışmasında manyetik rezonans ve düşey elektrik sondaj verilerinin bir boyutlu birleşik modellemesi GA ile gerçekleştirilmiştir. Pallero vd. (2017), Essa ve Munschy (2019) çalışmalarında gravite verileri PSO ile modellenmiştir.

Geleneksel ters çözüm yöntemlerinde, model özelliklerini belirleyen operatörler genelde Jacobian dizeyinin (matrisinin) hesabını gerektirir (ör. Sasaki, 1989; deGroot-Hedlin ve Constable, 1990, 2004; Portniaguine ve Zhdanov, 1999). Global yöntemlerse çoğunlukla Jacobian hesabına gereksinim duymaz ve bu yöntemlerde model kabalığı ile gözlenen ve hesaplanan veriler arasındaki çakışmanın eşzamanlı optimizasyonu, işlem maliyetini önemli ölçüde artırmaktadır. Bu nedenle, Karcıoğlu ve Gürer (2019)' da yuvarlatıcı Gauss süzgeci temelli alçak geçişli bir operatörün, model kabalığını kontrol etmek için Global Optimizasyon içerisinde kullanılabileceği gösterilmiştir. $\mathrm{Bu}$ çalışmada ise, Radyo-Manyetotellürik (RMT) verilerin PSO işleciyle iki boyutlu çözümünde, elde edilecek modelin özellikleri bir yüzdelik süzgeçten (percentile filter) faydalanılarak belirlenmiştir ve yuvarlatıcı süzgeçlere göre daha başarıı olabildiği gösterilmiştir.

Yüksek frekanslı değişimleri modelden atarken sınır bilgisini koruyabilen (Ataman vd., 1981) doğrusal olmayan yüzdelik süzgeç kullanılarak, görece belirgin yapı sınırlarına sahip modeller elde edilmesi hedeflenmiştir. Bu amaçla, istenen özellikler sağlanana kadar, yüzdelik süzgecin bir veya birkaç defa model parametreleri ile konvolüsyonu gerçekleştirilmiştir. Benzer şekilde, model kabalığı için kullanılan yuvarlatıcı operatörlerin bir defadan fazla uygulanması, geleneksel ters çözüm yöntemlerinde de görülmektedir (ör. Kelbert vd., 2014). Geliştirilen işleçte, yüzdelik süzgeç uygulanan model parametrelerinin gözlenen ve hesaplanan veri çakışmasını en iyi yapması beklenmiştir. Yani, yer altını temsil eden model parametrelerinin, parametrelerin süzgeç uygulandıktan sonraki değerleri olduğu varsayılmıştır.

Geliştirilen PSO işleci, önce kuramsal veri kümeleri üzerinde sınanmıştır; daha sonra arazi verilerine uygulanmıştır. Karşılaşıtırma amacıyla, hem yapay hem de arazi verileri yuvarlatıcılı tersçözüm ve Gauss süzgecinden faydalanan PSO işleçleriyle de modellenmiştir. 


\section{PARÇACIK SÜRÜSÜ OPTIMIZASYONU (PSO)}

PSO, popülasyon tabanlı bir evrimsel Global Optimizasyon işlecidir. Yöntemde, her yinelemede (iterasyon), önceden belirlenen bir popülasyon sayısı kadar model üretilir. Bu modeller değerlendirilir ve her bir modeli oluşturan model parametreleri güncellenir. Bir sonraki yineleme güncellenen modellerin değerlendirilmesi ile devam eder.

$\mathrm{N}$ adet modelden oluşan bir popülasyon için $(i=1,2, \ldots, N)$, herhangi yineleme "t" içerisinde üretilmiş modeller değerlendirildikten sonra, popülasyon içerisindeki modeller $\left(\mathrm{x}_{\mathrm{i}}\right)$ aşağıdaki şekilde güncellenir (Clerc ve Kennedy, 2002; Kennedy, 2003).

$\mathrm{V}_{\mathrm{i}}(\mathrm{t}+1)=\mathrm{x}\left(\mathrm{V}_{\mathrm{i}}(\mathrm{t})+\mathrm{C}_{1} \varphi_{1}\left(\mathrm{P}_{\mathrm{l}, \text { eniyi }}-\mathrm{x}_{\mathrm{i}}\right)+\mathrm{C}_{2} \varphi_{2}\left(\mathrm{P}_{\mathrm{g}, \text { eniyi }}-\mathrm{x}_{\mathrm{i}}\right)\right)$

$x_{i}(t+1)=x_{i}(t)+V_{i}(t+1)$

Denklem (1) ve (2)'ye göre, herhangi bir modelin yeni parametreleri, kendi mevcut parametrelerinin $\left(\mathrm{x}_{\mathrm{i}}\right)$, kendisinin mevcut yinelemeye kadar aldığı en iyi parametrelerin $\left(\mathrm{P}_{\mathrm{l}, \text { eniyi }}\right)$ ve ilgili yinelemeye kadar elde edilmiş en iyi modele ait model parametrelerinin $\left(\mathrm{P}_{\mathrm{g}, \text { eniyi }}\right)$ bir bileşkesidir.

Deneme yanılma işleminin doğal bir parçası olarak, denklem (2) ile güncellenen model parametreleri çözümden uzaklaşabilmektedir. Bunun sonucu olarak, popülasyon içerisindeki bir model, mevcut yinelemede en iyi değerlerine sahip olmayabileceği için çok zaman " $\mathrm{P}_{\mathrm{l}, \text { eniyi" }}$ ve " $\mathrm{i}_{i}$ " aynı olmaz. " $\mathrm{P}_{\mathrm{g}, \text { eniyi" }}$ ise, popülasyon içindeki modellerin tamamı kullanılarak belirlenebildiği gibi, bazen de belli kurallara göre seçilen bir kısmı gözetilerek belirlenir. Sabit kabul edilen " $\mathrm{C}_{1}$ " ve " $\mathrm{C}_{2}$ ", her bir bileşenin katkısını kontrol eder. Düzgün dağılımlı rastgele değerler " $\varphi_{1}$ " ve " $\varphi_{2}$ ", güncellenen modellerin, parametre uzayında daha geniş bir alana saçılmasını sağlar. Yine bir sabit olan " $X$ " ise sönümlenme katsayısıdır ve model parametrelerinin yinelemeler arasında salınım yapmasının önüne geçmeyi amaçlar. Sönümlenme katsayısı aşağıdaki şekilde tanımlanır.

$x=2 k /\left|2-c-\left(c^{2}-4 c\right)^{1 / 2}\right|$
Denklemde $\mathrm{C}=\mathrm{C}_{1}+\mathrm{C}_{2}$ ve $\mathrm{c} \geq 4$ 'dür. Clerc ve Kennedy (2002) çalışmasında gerçekleştirilen analizler sonucunda en uygun parametrelerin, $\mathrm{C}=4.1$ ve $X=0.7298$ olduğu sonucuna varılmıştır; $k$ katsayısı da bu değerleri sağlamak için $k=\sim 0.99994$ seçilmiştir. Birçok çalışmada bu parametreler benimsenmiştir (ör. Kennedy, 2003; Montes de Oca vd., 2008; Li ve Yao, 2011) ve bu çalışmada da aynı değerler kullanılmıştır.

Her bir yinelemede düz çözümü gerçekleştirilerek değerlendirilecek model sayısı olan popülasyon, yöntemin çözüm süresini belirleyen en önemli parametrelerden birisidir. Bu çalışmada, $\mathrm{Li}$ ve Yao (2011) çalışmasında verilmiş olan aşağıdaki denklem kullanıımıştır.

$N=4+3^{*} \log (n)$

Denklemde "N" popülasyonu; " $n$ " ise her bir modelin içerdiği model parametresi sayısıdır $\left(x i=m_{1}, m_{2}, .\right.$. , $\mathrm{mn})$. Bu denklem, büyük problemler için dahi görece düşük popülasyon sayıları önermektedir.

\section{PSO Yönteminde Alçak Geçişli Filtrelerin Uygulanması}

PSO'da geleneksel yaklaşım, rastgele başlangıç modellerinden oluşan bir popülasyondan yola çıkarak model parametrelerinin $(m)$ aranmasıdır. Geliştirilen işleçte ise, kullanıcı tarafından sağlanan başlangıç modelinden $(\mathrm{m} 0)$ farkı ifade eden parametre değişim yöneyi (vektörü) " $\Delta \mathrm{m}$ ” aranmıştır.

$m=m_{0}+\Delta m$

Böylece, jeofizik modellemede önemli bir unsur olan, diğer çalışmalardan elde edilmiş bilginin yok sayılmasının önüne geçilmektedir. Geliştirilen PSO işleci ile gerçekleştirilen denemelerde, başlangıç modeli kullanıldığında hedeflenen karekök ortalama (RMS) hata seviyelerine daha çabuk ulaşıldığı gözlenmiştir.

Global Optimizasyon'da eşzamanlı olarak, RMS hata düşürülürken belirli özelliklerdeki yapı sınırlarının aranması, işlem süresini önemli miktarda 
arttırmaktadır. Ayrıca, PSO ve benzeri yöntemler, rastgele doğaları nedeniyle özellikle veri duyarlılığının (sensitivity) düştüğü bölgelerde çok sayıda sahte yapı (artifact) ve yüksek frekanslı iletkenlik değişimleri oluşturmaya meyillidir.

Bu amaçla, yuvarlatıcı süzgeçlerden faydalanılması mümkündür (ör. Gauss süzgeci). Ancak jeolojik modeller oluşturulurken, genellikle yeraltındaki yapıların yatay ve düşey yönde belirli sınırları bulunduğu varsayılır (Mehanee ve Zhdanov, 2002). Özellikle ekonomik amaçlı çalışmalarda, görece keskin yapı sınırları sıklıkla aranmaktadır. Yuvarlatıcılı operatörlerse çoğu zaman bulanık yapı sınırları ve yorumu zor modeller ortaya koymaktadır. Buna karşın, uygulanabilecek doğrusal keskinleştirici operatörler de (sharpening filters) gürültünün yükseltilmesine sebep olur (Hodgson vd., 1985). Doğrusal olmayan sıralama süzgeçleri ise (rank filters) belirtilen bu sorunların önüne geçebilmektedir. Sıralama süzgeçlerinin en önemli özelliği, yüksek frekanslı değişimleri giderirken sınır bilgisini koruyabilmeleridir (Ataman vd., 1981; Hodgson vd., 1985). Bu süzgeçlerden, özellikle görüntü işleme amacıyla en sık kullanılanlarından biri yüzdelik süzgeçtir. Yüzdelik süzgeçler basitçe aşağıdaki biçimde uygulanır.

Model ağında birbirine komşu parametrelerini kapsayan dörtgen biçimli süzgeç penceresi "P" içerisinde yer alan "np" adet değer küçükten büyüğe sıralanarak bir parametre yöneyi oluşturulur;

$\left(m_{P, 1}, m_{P, 2}, \ldots, m_{P, n p-1}, m_{P, n p}\right)$

Burada, en küçük değer, mp,1, \%0; en büyük değer, $\mathrm{m}_{\mathrm{P}, \mathrm{np}}$ \%100 değerine karşılık gelmektedir. Süzgeç, merkez hücreye, pencere içerisinde istenen yüzdelik değerine (y) karşılık gelen komşusunun değerini atar. Filtre penceresi, bu işlem bütün hücreler için uygulanana kadar kaydırılır. Yüzdelik süzgeçte, $y=0.5$ medyan süzgece karşılık gelmektedir, $y=0$ ve 100 ise sırasıyla, süzgeç penceresi içerisindeki en küçük (minimum filter) ve en büyük değerleri (maximum filter) merkez hücreye atamaktadır. Anlaşılacağı üzere, bu filtreler için Gauss süzgecinde olduğu gibi sabit bir filtre çekirdeği (filter kernel) oluşturulamaz.
Bu çalışmada, yüzdelik süzgeçleme amacıyla, bir Python programlama dili kütüphanesi olan SciPy içerisinde bulunan işleç kullanılmıştır (Virtanen vd., 2020).

Geliştirilen PSO işlecinde yüzdelik süzgeç aşağıdaki şekilde uygulanmıştır;

$\mathrm{m}_{\mathrm{k}}=\left(\mu \mathrm{P}_{\mathrm{y}}(\mathrm{m})\right)$

Burada $P$, yüzdelik süzgeç operatörünü, y ise yüzdelik değerini temsil etmektedir. Yüzdelik süzgeç, model istenen şartları sağlayana kadar, gerekirse birden fazla defa uygulanmıştır. Denklem (7)'de $\mu$ yüzdelik süzgecin kaç defa uygulanacağını ifade etmektedir. Uygulamada, y ve $\mu$ parametreleri kullanıcı tarafından deneme yanılma ile belirlenmektedir ve modelleme boyunca sabit kalmaktadır.

Buna göre, süzgeçlenmiş model parametreleri " $m_{k}$ " ile ifade edilirse, PSO işleci tarafından enküçüklenmesi (minimize edilmesi) istenen denklem aşağıdaki gibidir.

$\mathrm{U}=\alpha_{\mathrm{r}} \mathrm{s}\left(\mathrm{m}_{\mathrm{k}}\right)+\left\{\left\|\mathrm{Wd}-\mathrm{WF}\left[\mathrm{m}_{\mathrm{k}}\right]\right\|^{2}\right\}$

Denklemde, W veri ağırlık dizeyi, d gözlenen veri, $F\left[m_{k}\right]$ ise PSO işleci tarafından üretilen modelin düz çözüm sonucudur. Denklemde $s\left(m_{k}\right)$, süzgeçlenmiş değerlerin MGS (Minimum Gradient Support) değerini ifade eder. MGS, Portniaguine ve Zhdanov (1999) tarafından tanımlanan, odaklamalı tersçözüm (focusing inversion) yöntemi için geliştirilmiş bir operatördür. Yapı sınırları, bu operatörün değerinin artmasına sebep olmaktadır, ancak özdirenç farkılıklarının yüksek olması operatörün değerini aşırı etkilememektedir. Bu nedenle, MGS yapıları en küçüklemeyi amaçlarken, büyük özdirenç farklılıklarını en küçüklenmek istenen denkleme fazla yansıtmamaktadır. MGS operatörünün, enküçüklenmesi istenen denkleme katkısı, küçük bir katsayı olan ar ile kontrol edilmiştir. Bu nedenle, işleç tarafından modelde yeni bir sınır oluşturulduğu zaman, gözlenen ve hesaplanan veriler arasındaki çakışma yeterince iyileşmiyorsa Denklem (8)'in değeri büyüyecektir. Böylece, PSO işlecinin bu sınırı modele katması engellenecektir. 


\section{KURAMSAL VE ARAZI VERILERININ MODELLENMESi}

Geliştirilen işlecin sınanması amacıyla, Şekil 1a ve Şekil 5a' da verilen kuramsal modellerden elde edilen veri kümeleri kullanılmıştır. Modellerden ilki, bir yalıtkan ve iki iletken bloktan ibarettir. Birinci model için kuramsal veriler, üç frekans $(26,16,5 \mathrm{kHz})$ için 39 noktada hesaplanmış TE ve TM modu görünür özdirenç, faz ve TE modu tipper anomalileridir.
Modellemeden önce verilere standart sapmalarının $\% 5$ ¡ kadar Gauss gürültüsü ilave edilmiştir. Veriler, Occam yaklaşımı ile yuvarlatıcılı ters çözümle (Şekil 1b), PSO işlecinde Gauss filtresi uygulamasıyla (Şekil 1c) ve son olarak PSO işlecinde yüzdelik süzgeç uygulamasıyla (Şekil 1d) modellenmiştir. Her üç deneme de 1 RMS hata ile sonuçlanmıştır; elde edilen modellere ait gözlenen ve hesaplanan verilerin çakışması Şekil 2, Şekil 3 ve Şekil 4'de sunulmuştur.

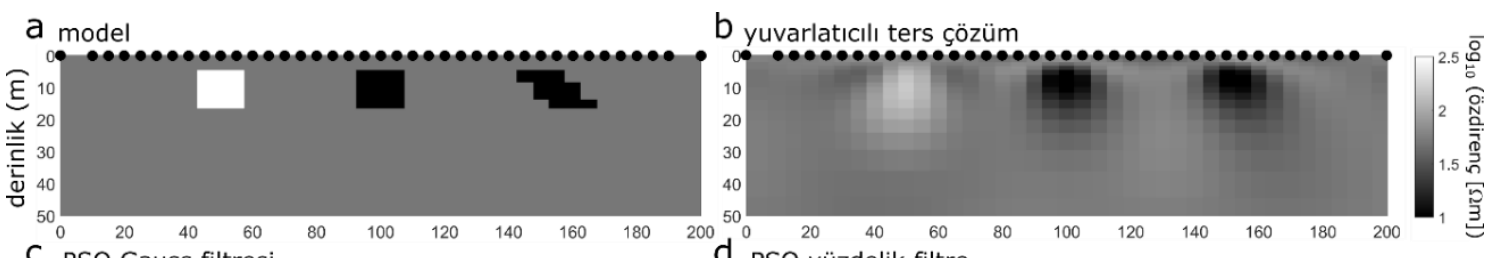

b yuvarlatıcılı ters çözüm

d PSO yüzdelik filtre
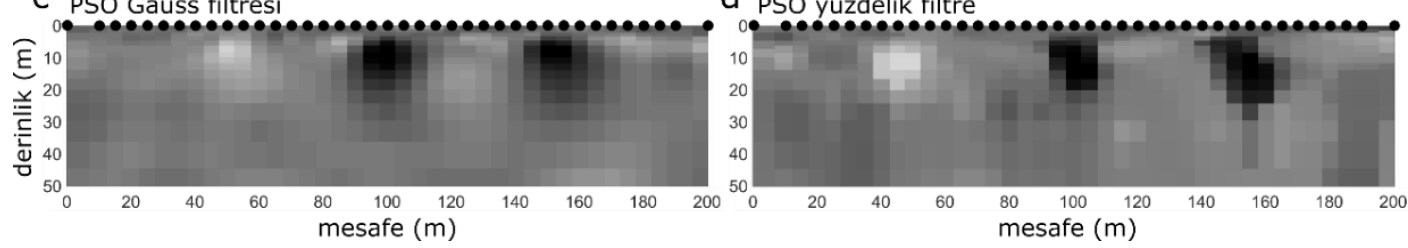

Şekil 1. a) Yapay veri kümesinin üretilmesi için kullanılan model, b) Yuvarlatıcılı ters çözüm sonucu, c) Gauss filtresi ile PSO sonucu, d) Yüzdelik filtre ile PSO sonucu. Elde edilen modeller, tanımlanan yapılarla arkaplan özdirenci arasındaki farkın vurgulanması için logaritmik skala kullanılarak çizdirilmiştir.

Figure 1. a) Model used for generating the synthetic dataset, b) Smooth inversion result, c) PSO result with Gauss filter, d) PSO result with percentile filter. The recovered models are plotted using a logarithmic scale to emphasize the resistivity difference between the defined structures and the background resistivity.
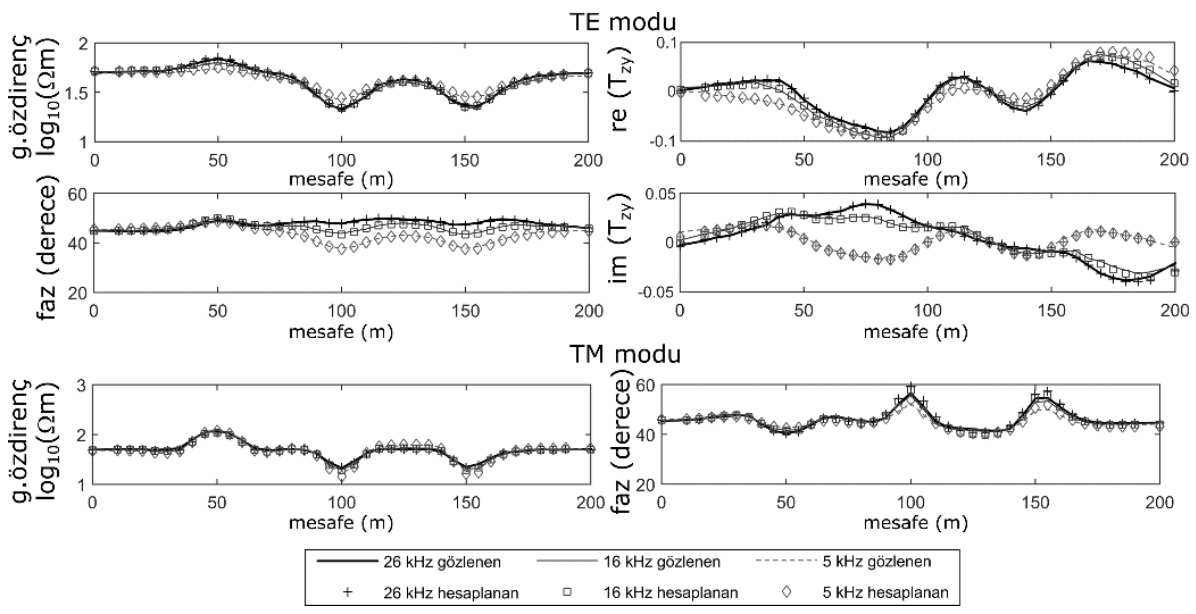

Şekil 2. Yapay verilerin yuvarlatıcılı ters çözümü sonucunda elde edilen modele ait gözlenen ve hesaplanan verilerin çakışması. Şekilde, görünür özdirenç verileri, tanımlanan yapılarla arkaplan özdirenci arasındaki farkın vurgulanması için logaritmik çizdirilmiştir.

Figure 2. Observed-Calculated data fitting of the model obtained from the smooth inversion of the synthetic dataset. In the figure, apparent resistivity data are plotted logarithmically to emphasize the resistivity difference between the defined structures and the background resistivity. 

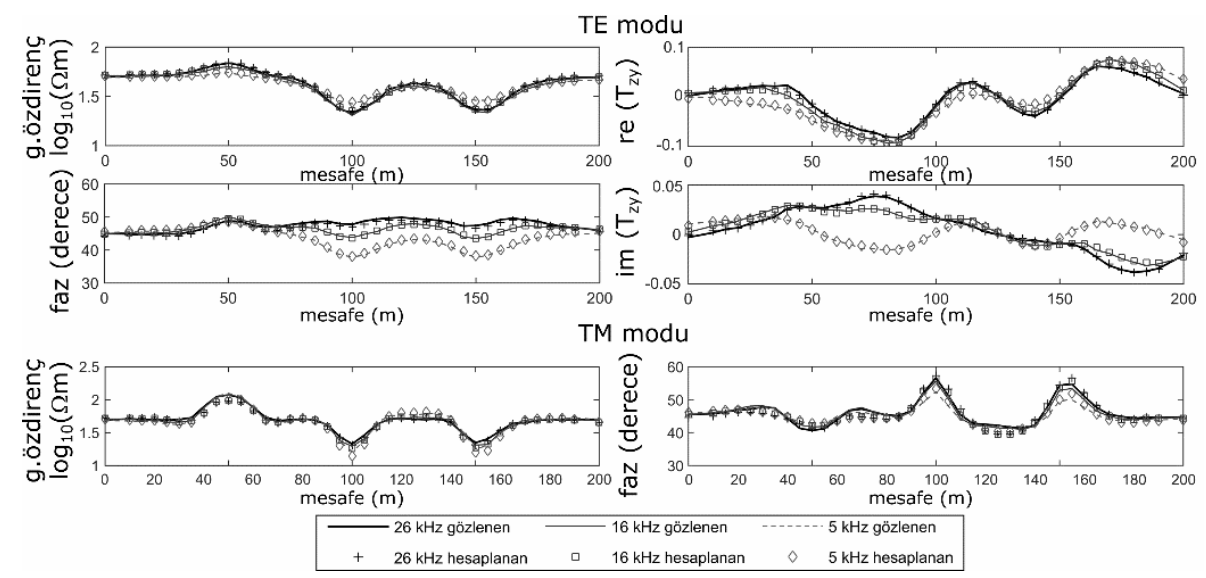

Şekil 3. PSO işleci ile Gauss süzgeci kullanılması sonucunda yapay veri kümesinden elde edilen modele ait gözlenen ve hesaplanan verilerin çakışması. Şekilde, görünür özdirenç verileri, tanımlanan yapılarla arkaplan özdirenci arasındaki farkın vurgulanması için logaritmik çizdirilmiştir.

Figure 3. Observed-Calculated data fitting of the model obtained from the synthetic dataset by using the PSO algorithm with Gaussian filter. In the figure, apparent resistivity data are plotted logarithmically to emphasize the resistivity difference between the defined structures and the background resistivity.

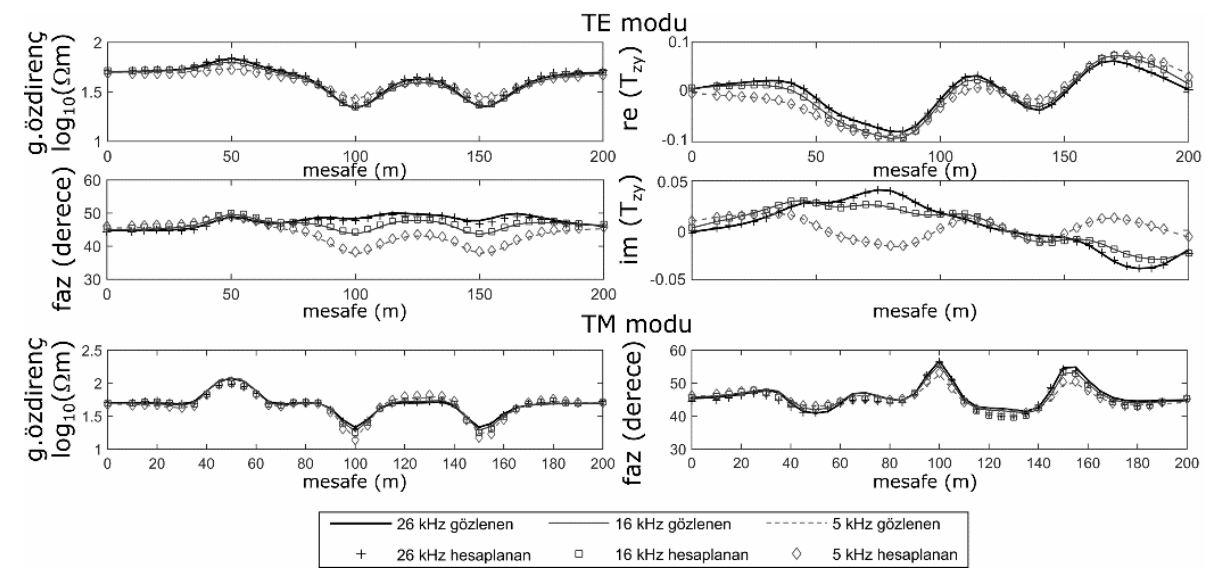

Şekil 4. PSO işleci ile yüzdelik süzgeç kullanılması sonucunda yapay veri kümesinden elde edilen modele ait gözlenen ve hesaplanan verilerin çakışması. Şekilde, görünür özdirenç verileri, tanımlanan yapılarla arkaplan özdirenci arasındaki farkın vurgulanması için logaritmik çizdirilmiştir.

Figure 4. Observed-Calculated data fitting of the model obtained from the synthetic dataset by using the PSO algorithm with percentile filter. In the figure, apparent resistivity data are plotted logarithmically to emphasize the resistivity difference between the defined structures and the background resistivity.

İkinci kuramsal model (Şekil 5a), arazi verisinin toplandığı ortama benzer nitelikte hazırlanmıştır. Modelde, yüzeyde $100 \Omega$ m özdirençli örtü ve altında iletken bir normal fay tarafından bölümlenmiş 1000 $\Omega m$ özdirençli yapı bulunmaktadır. Bu yapay veri kümesi için tanımlanan model üzerinde belirlenen 25 noktada, 234,183, 75, 16.4, $12.1 \mathrm{kHz}$ frekansları için görünür özdirenç ve faz verileri hesaplanmıştır. Daha sonra, bu verilerin stadart sapmalarının $\% 5^{\prime} i$ kadar Gauss gürültüsü eklenmiştir. 
Yapay veri kümesi önce Occam yaklaşımını kullanan yuvarlatıcılı ters çözüm işleciyle (Şekil 5b, Şekil 6), ardından PSO işlecinde Gauss süzgeci kullanılarak (Şekil 5c, Şekil 7), son olarak da PSO ile yüzdelik süzgeç kullanılarak (Şekil 5d, Şekil 8) modellenmiştir ve sonuçları karşılaştırılmıştır. Yüzdelik filtre, model parametrelerine bir defa uygulanmıştır ve filtre için yüzdelik değeri \%17 olarak deneme yanılma ile belirlenmiştir. Her üç modelleme işlemi de gözlenen ve hesaplanan veriler arası çakışma 1 RMS değerine ulaştığında durdurulmuştur.

Kuramsal veri kümeleri için elde edilen modeller kıyaslandığında, kullanılan bütün işleçlerin tanımlanan yapıları belirleyebildiği gözlenmektedir. Elde edilen modeller (Şekil 1, Şekil 5) incelendiğinde, yüzdelik süzgeç ile uygulanan PSO işlecinin (Şekil 1d, Şekil $5 d$ ), yuvarlatıcı operatörler kullanan işleçlere göre daha belirgin yapı sınırları sağladığı görülmektedir.

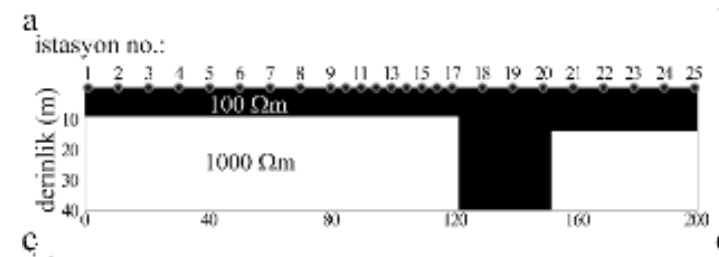

istasyon no.:

b

istasyon no.:
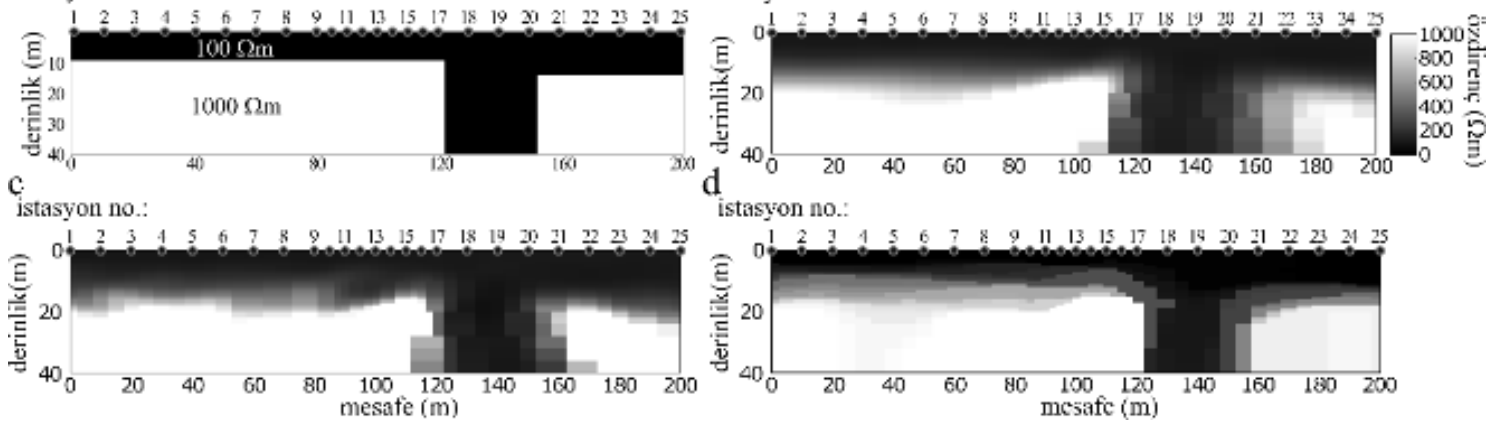
istasyon no.

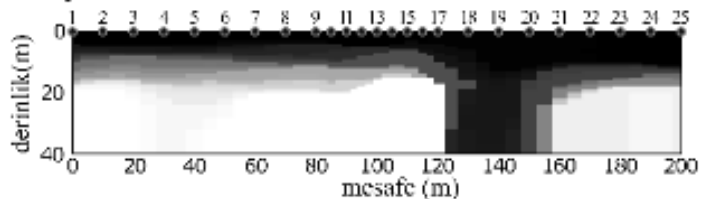

Şekil 5. a) Yapay veri kümesinin üretilmesi için kullanılan fay modeli, b) Yuvarlatıcılı ters çözüm sonucu, c) Gauss filtresi ile PSO sonucu, d) Yüzdelik filtre ile PSO sonucu.

Figure 5. a) Fault model used for generating the synthetic dataset, b) Smooth inversion result, c) PSO result with Gauss filter, d) PSO result with percentile filter.
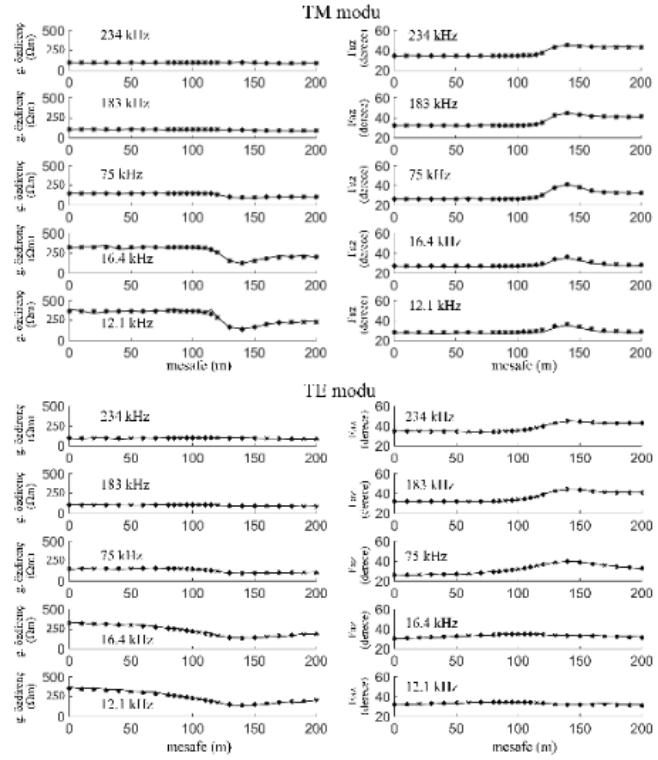

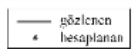

Şekil 6. Kuramsal fay modeli için yuvarlatıcılı ters çözümle elde edilen modele ait gözlenen ve hesaplanan verilerin çakışması.

Figure 6. Observed-Calculated data fitting of the model obtained from the smooth inversion for the synthetic fault model.
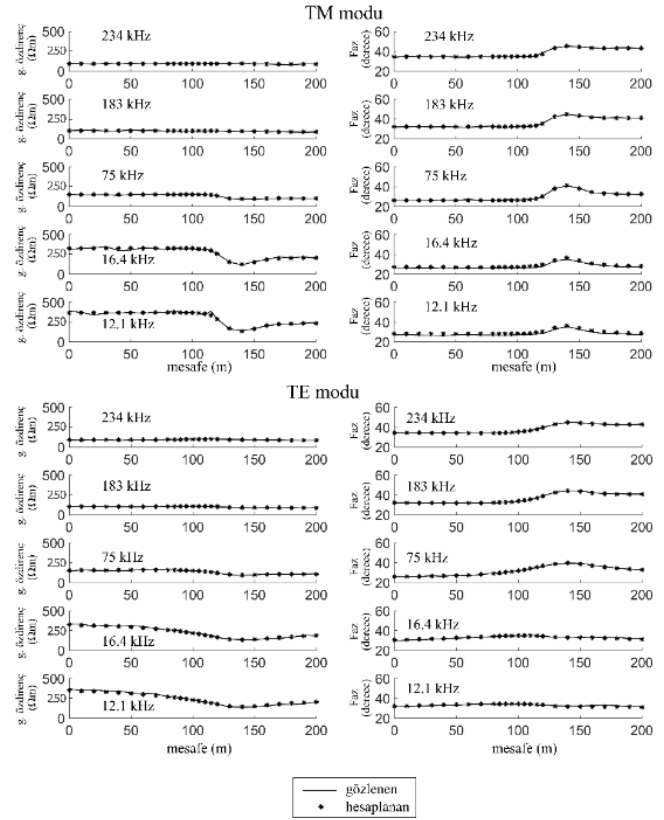

Şekil 7. Kuramsal fay modeli için Gauss süzgeciyle PSO kullanılarak elde edilen modele ait gözlenen ve hesaplanan verilerin çakışması.

Figure 7. Observed-Calculated data fitting of the model obtained for the synthetic fault model by using PSO with Gaussian filter. 


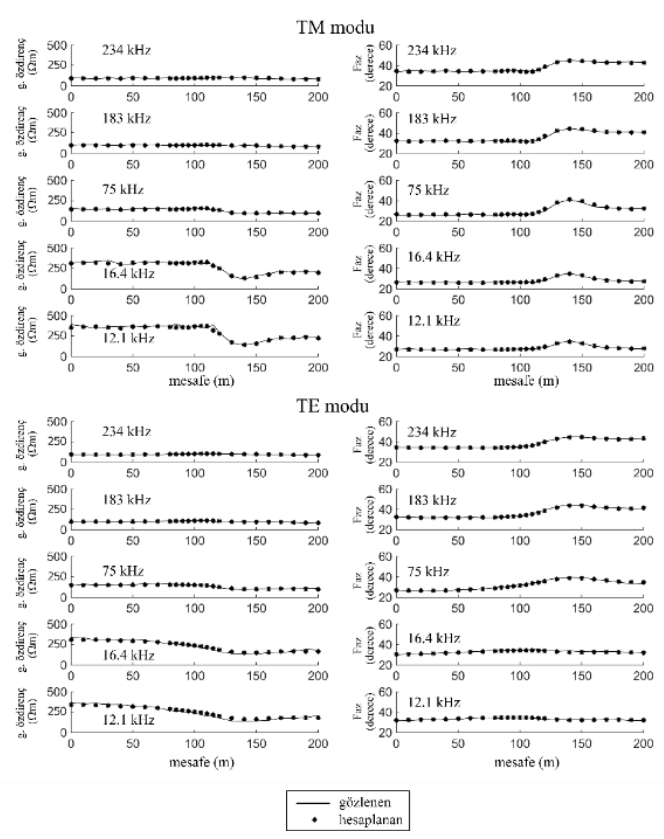

Şekil 8. Kuramsal fay modeli için yüzdelik süzgeç ile PSO kullanılarak elde edilen modele ait gözlenen ve hesaplanan verilerin çakışması.

Figure 8. Observed-Calculated data fitting of the model obtained from the synthetic fault model by using PSO with percentile filter.

Çalışmada kullanılan arazi verileri, Candansayar ve Tezkan (2008) tarafından Almanya'nın Köln şehri yakınında yer alan Kerpen bölgesinde toplanmıştır. Verilerin toplandığı bölgenin yüzeye yakın bölümü, iletken lös katmanı tarafından örtülmüş görece yalıtkan çakıllarla ifade edilmektedir. Ayrıca verilerin toplandığı hat, olası bir normal fayın üzerinden geçmektedir (Streich 2003; Candansayar ve Tezkan, 2008). Bu veriler daha önce Candansayar ve Tezkan (2008), Özyıldııım vd. (2017) çalışmalarında yuvarlatıcılı ters çözüm işleçleriyle değerlendirilmiştir.

Arazi verileri 25 istasyonda, TM modunda 198, 65.8, $12.1 \mathrm{kHz}$ ve TE modunda $234,183,75,16.4 \mathrm{kHz}$ frekansları için görünür özdirenç ve fazları içermektedir. Veriler modellenirken genliklerinin \%5'i oranında ağırlıklandırıımıştır.

Arazi verilerinin, ilk olarak Occam yaklaşımıyla yuvarlatıcılı ters çözümü gerçekleştirilmiş ve 1 RMS hataya sahip model elde edilmiştir (Şekil 9a, Şekil 10).
Veriler PSO işleci ile modellenirken, öncelikle yuvarlatıcılı ters çözümün eşleniği olarak değerlendirilebilecek Gauss süzgeci uygulanmıştır. Her yinelemede 32 model üretilmiştir ve 2400 yineleme sonucunda 1.14 RMS hataya sahip model elde edilmiştir (Şekil 9b, Şekil 11). Son olarak, arazi verileri PSO işleci yüzdelik süzgeç kullanılarak modellenmiştir. Yüzdelik filtre, model parametrelerine bir defa uygulanmıştır ve filtre için yüzdelik değeri \%17 olarak deneme yanılma ile belirlenmiştir. Her yinelemede 32 model üretilmiştir ve 1500 yineleme sonucunda 1.1 RMS hataya sahip model elde edilmiştir (Şekil 9c, 12).

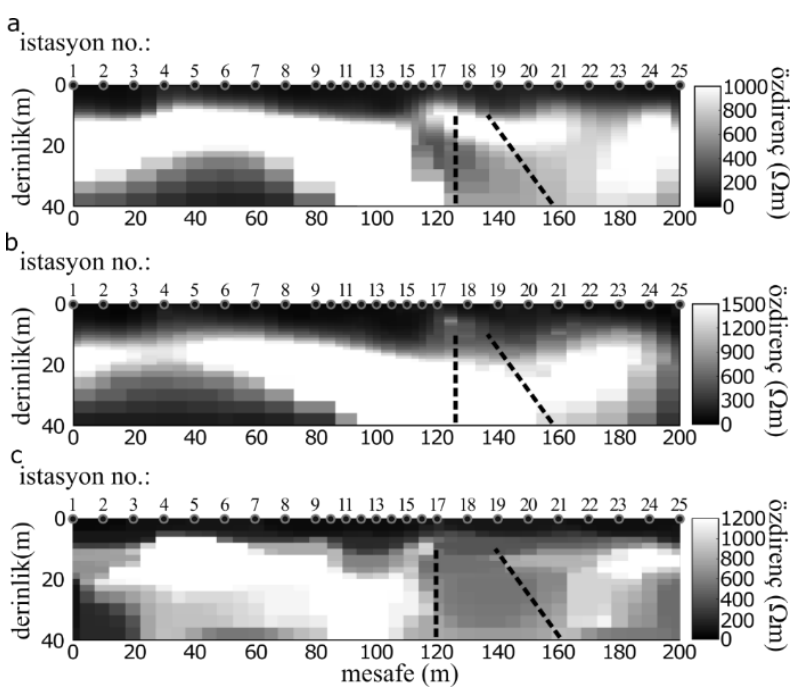

Şekil 9. a) Arazi verilerinin yuvarlatıcılı ters çözümü sonucu elde edilen model, b) PSO işleci ile Gauss süzgeci kullanılması sonucunda elde edilmiş model, c) PSO işleci ile yüzdelik süzgeç kullanılması sonucunda elde edilmiş model.

Figure 9. a) Model obtained from the smooth inversion of the field data, b) Model obtained by using the PSO algorithm with Gaussian filter, c) Model obtained by using the PSO algorithm with percentile filter.

Yuvarlatıcılı ters çözüm ile elde edilen model incelendiğinde, en düşük RMS hata değerine sahip olduğu görülmektedir. Candansayar ve Tezkan (2008), Özyıldırım vd. (2017) çalışmalarında varlığı gösterilen faylar elde edilen modelde görülmekle birlikte, kullanılan durağanlaştırııı nedeniyle sınırlar bulanıktır. Ayrıca, 16. ve 22. istasyonlar arasında elde edilen 
yatay uzanımlı yalıtkan, bilinen faylarla tam uyuşmamaktadır.

PSO işleci ile elde edilen iki model kıyaslandığında, Gauss süzgeci ile elde edilen modeldeki yapı sınırları, yuvarlatıcı süzgeç nedeniyle belirgin biçimde elde edilememiştir. Yüzdelik süzgeç ile elde edilen modelde ise bilinen fayların daha başarılı belirlendiği gözlenmektedir. İki model için gerçekleştirilen yineleme sayıları kıyaslandığında da yüzdelik süzgecin Gauss süzgecine kıyasla hızlı sonuç sağladığı görülmektedir.

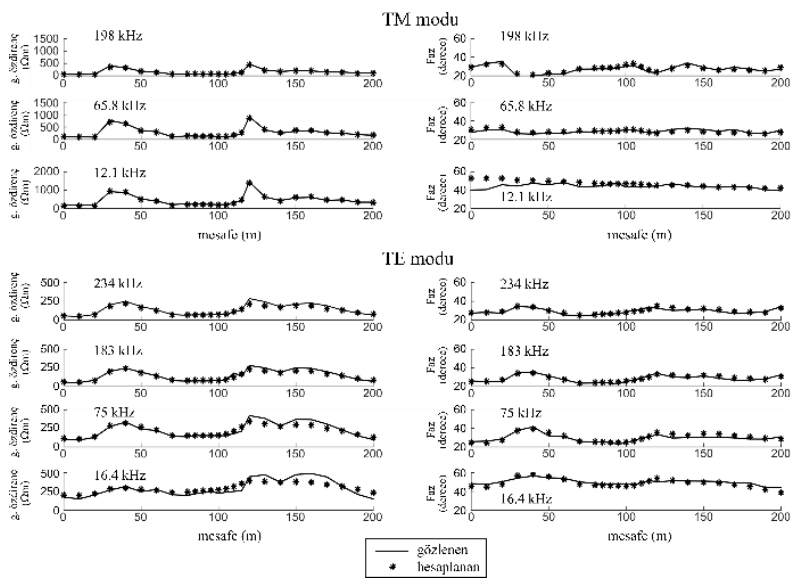

Şekil 10. Yuvarlatıcılı ters çözüm sonucunda arazi verilerinden elde edilen modele ait gözlenen ve hesaplanan verilerin çakışması.

Figure 10. Observed-Calculated data fitting for the model obtained from the smooth inversion of the field data.

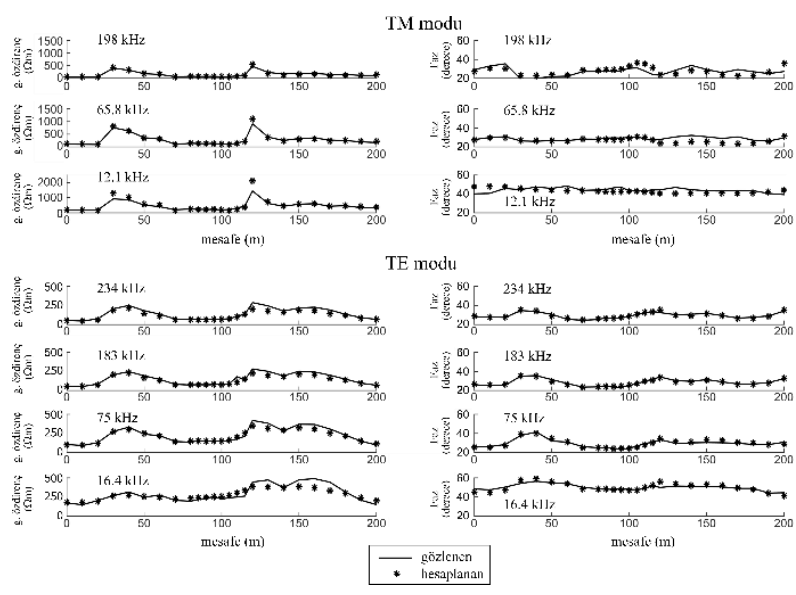

Şekil 11. PSO işleci ile Gauss süzgeci kullanılması sonucunda arazi verilerinden elde edilen modele ait gözlenen ve hesaplanan verilerin çakışması.

Figure 11. Observed-Calculated data fitting for the model obtained from the field data by using the PSO algorithm with Gaussian filter.

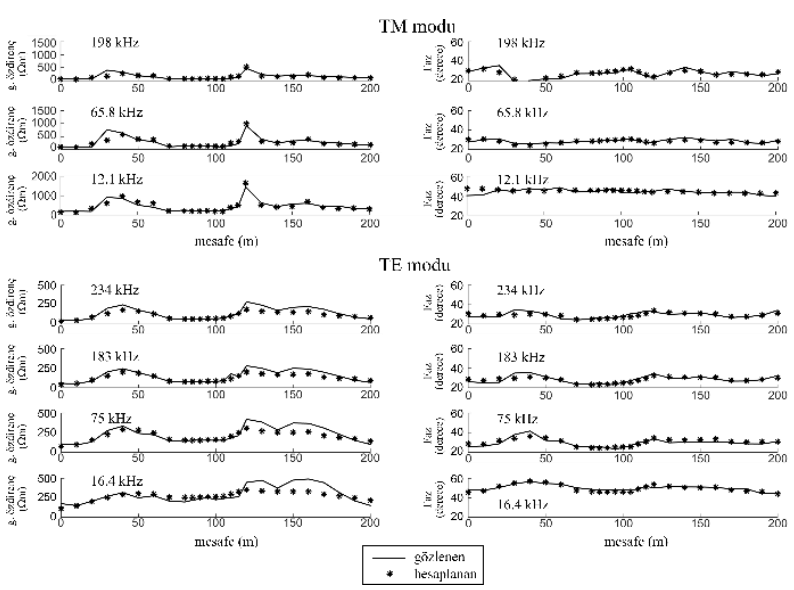

Şekil 12. PSO işleci ile yüzdelik süzgeç kullanılması sonucunda arazi verilerinden elde edilen modele ait gözlenen ve hesaplanan verilerin çakışması.

Figure 12. Observed-Calculated data fitting for the model obtained from the field data by using the PSO algorithm with percentile filter.

\section{SONUÇLAR VE TARTIŞMA}

Global Optimizasyon teknikleri, geleneksel ters çözüme kıyasla daha fazla işlem süresi gerektirdiğinden, çok boyutlu jeofizik modelleme için uygulanabilir olması ancak son 15 yılda, kişisel bilgisayarların paralel işlem yapabilme özelliklerindeki sıçrama ile gerçekleşmiştir. Global Optimizasyon yöntemleri, ters çözüm yöntemlerine kıyasla paralel çalışan işlemcilerden daha verimli faydalanmaktadır. $\mathrm{Bu}$ nedenle, global yöntemlerin jeofizik uygulamaları için verimli yaklaşımların belirlenmesi önem kazanmaktadır.

Karcıoğlu ve Gürer (2019)'da global yöntemlerin RMT verilerinin modellenmesi amacıyla temelinde alçak geçişli Gauss süzgeci olan yuvarlatıcı bir operatörün kullanılabileceği gösterilmiştir. Ancak, daha belirgin sınır bilgisi elde edilmek istendiğinde, yuvarlatıcı süzgeçlerin kullanılması kolay yorumlanabilir sonuçlar sağlamakta yetersiz kalmaktadır.

Bu çalışmada, hem model parametrelerindeki yüksek frekanslı değişimleri yok eden hem de yapı sınırlarını korumada daha başarılı olan yüzdelik süzgecin, PSO işleciyle RMT verilerinin modellenmesi için kullanılması önerilmiştir. Hem yapay hem de arazi veri kümelerinde gerçekleştirilen denemelerde, yüzdelik süzgeç, Gauss operatörlerine kıyasla daha başarılı olmuştur. 
Yapay veri kümeleri ile gerçekleştirilen çalışmalarda, yüzdelik süzgeç ile elde edilen modellerde yapı sınırlarının daha belirgin olduğu görülmüştür. Yüzdelik süzgeç, arazi veri kümesinde varlığı ve konumu önceki çalışmalardan bilinen fayları da daha başarıı göstermiştir. Ayrıca, gereken yineleme sayısının Gauss süzgeciyle gerçekleştirilen uygulamalardan daha az olduğu görülmüştür. Yüzdelik süzgeçler ve modelleme işlemi içerisindeki uygulanması PSO için özelleşmiş olmadığından, önerilen süzgecin diğer Global Optimizasyon yöntemlerinde de uygulanması mümkündür (ör. genetik algoritmalar).

\section{KATKI BELIRTME}

Düz ve yuvarlatıcılı ters çözüm Manyetotellürik algoritmalarının geliştirilmesinde katkısı bulunan Prof.Dr. Emin Candansayar'a, Dr. İsmail Demirci'ye, Dr. Özcan Özyıldırım'a, Dr. Erhan Erdoğan'a, Dr. Cem Demirel'e teşekkür ederim. RMT arazi verisini sağlayan Prof.Dr. Emin Candansayar ve Prof.Dr. Bülent Tezkan'a teşekkür ederim.

\section{KAYNAKLAR}

Akça, I., Başokur, A.T., 2010. Extraction of structurebased geoelectric models by hybrid genetic algorithms. Geophysics 75 (1), F15-F22.

Akça, I., Günther, T., Müller-Petke, M., Basokur, A.T., Yaramanci, U., 2014. Joint parameter estimation from magnetic resonance and vertical electric soundings using a multiobjective genetic algorithm. Geophys. Prospect. 62 (2), 364-376.

Ataman, E., Aatre, V., \& Wong, K., 1981. Some statistical properties of median filters. IEEE Transactions on Acoustics, Speech, and Signal Processing, 29(5), 1073-1075.

Attwa, M., Akca, I., Basokur, A. T., \& Günther, T., 2014. Structure-based geoelectrical models derived from genetic algorithms: a case study for hydrogeological investigations along Elbe River coastal area, Germany. Journal of Applied Geophysics, 103, 57-70.

Balkaya, Ç., Göktürkler, G., Ekinci, Y. L., \& Turan, S., 2014. Metaheuristics in applied geophysics. Metaheuristics and Engineering, 133.
Candansayar, M.E., Tezkan, B., 2008. Twodimensional joint inversion of radiomagnetotelluric and direct current resistivity data. Geophys. Prospect. 56 (5), 737-749.

Clerc, M., Kennedy, J., 2002. The particle swarmexplosion, stability, and convergence in a multidimensional complex space. IEEE Trans. Evol. Comput. 6 (1), 58-73.

deGroot-Hedlin, C., Constable, S., 1990. Occam inversion to generate smooth, 2-dimensional models from magnetotelluric data. Geophysics 55 (12), 1613-1624.

de Groot-Hedlin, C., \& Constable, S., 2004. Inversion of magnetotelluric data for $2 \mathrm{D}$ structure with sharp resistivity contrasts. Geophysics, 69(1), 78-86.

Essa, K. S., \& Munschy, M., 2019. Gravity data interpretation using the particle swarm optimisation method with application to mineral exploration. Journal of Earth System Science, 128(5), 1-16.

Hodgson, R. M., Bailey, D. G., Naylor, M. J., Ng, A. L. M., \& McNeill, S. J., 1985. Properties, implementations and applications of rank filters. Image and Vision Computing, 3(1), 314.

Karcıoğlu, G., Gürer, A., 2019. Implementation and model uniqueness of Particle Swarm Optimization method with a 2D smooth modeling approach for Radio-Magnetotelluric data. Journal of Applied Geophysics, 169, 37-48.

Kelbert, A., Meqbel, N., Egbert, G. D., \& Tandon, K., 2014. ModEM: A modular system for inversion of electromagnetic geophysical data. Computers \& Geosciences, 66, 40-53.

Kennedy, J., 2003. Bare bones particle swarm. Proc. IEEE SIS, Apr. 2003, pp. 80-87.

Li, X., Yao, X., 2011. Cooperatively Coevolving Particle Swarms for large Scale Optimization. IEEE Trans. Evol. Comput. 16 (2), 210-224.

Mehanee, S., Zhdanov, M., 2002. Two-dimensional magnetotelluric inversion of blocky geoelectrical structures. Journal of Geophysical Research: Solid Earth, 107(B4), EPM-2. 
Montes de Oca, M.A., Van den Enden, K., Stützle, T., 2008. Incremental particle swarmguided local search for continuous optimization. In: Blesa, M.J., vd. (Eds.), LNCS 5296. Proceedings of the InternationalWorkshop on HybridMetaheuristics. Springer, Berlin, Germany, pp. 72-86.

Montesinos, F.G., Arnoso, J., Vieira, R., 2005. Using a genetic algorithm for 3-D inversion of gravity data in Fuerteventura (Canary Islands). Int. J. Earth Sci. 94 (2), 301-316.

Moorkamp,M., Jones, A.G., Eaton, D.W., 2007. Joint inversion of teleseismic receiver functions and magnetotelluric data using a genetic algorithm: are seismic velocities and electrical conductivities compatible? Geophys. Res. Lett. 34, L16311.

Moorkamp,M., Jones, A.G., Fishwick, S., 2010. Joint inversion of receiver functions, surface wave dispersion and magnetotelluric data. J. Geophys. Res. 115 (2010), B04318.

Özyıldırım, Ö., Candansayar, M. E., Demirci, İ., \& Tezkan, B., 2017. Two-dimensional inversion of magnetotelluric/radiomagnetotelluric data by using unstructured mesh. Geophysics, 82(4), E197-E210.

Pallero, J.L.G., Fernández-Martínez, J.L., Bonvalot, S., Fudym, O., 2017. 3D gravity inversion and uncertainty assessment of basement relief via Particle Swarm Optimization. J. Appl. Geophys. 139, 338-350.

Pekşen, E., Yas, T., Kayman, A. Y., \& Özkan, C., 2011. Application of particle swarm optimization on self-potential data. Journal of Applied Geophysics, 75(2), 305-318.

Pekşen, E., Yas, T., \& Kıyak, A., 2014. 1-D DC resistivity modeling and interpretation in anisotropic media using particle swarm optimization. Pure and Applied Geophysics, 171(9), 2371-2389.

Portniaguine, O., \& Zhdanov, M. S., 1999. Focusing geophysical inversion images. Geophysics, 64(3), 874-887.

Sasaki, Y., 1989. Two-dimensional joint inversion of magnetotelluric and dipole-dipole resistivity data. Geophysics 54, 254-262.
Sen, M. K., Stoffa, P. L., 2013. Global optimization methods in geophysical inversion. Cambridge University Press.

Streich, R., 2003. Geophysical Prospecting of Suspected Holocene Fault Activity in the Lower Rhine Embayment. Ph.D. thesis. Potsdam University.

Virtanen, P., Gommers, R., Oliphant, T. E., Haberland, M., Reddy, T., Cournapeau, D., Burovski, E., Peterson, P., Weckesser, W., Bright, J., van der Walt, S.J., Brett, M., Wilson, J., Millman, K. J., Mayorov, N., Nelson, A.R.J., Jones, E., Kern, R., Larson, E., Carey, C.J., Polat, I., Feng, Y., Moore, E. W., VanderPlas, J., Laxalde, D., Perktold, J., Cimrman, R., Henriksen, I., Quintero, E.A., Harris, C.R., Archibald, A.M., Ribeiro, A.H., Pedregosa, F., van Mulbregt, P., 2020. SciPy 1.0: fundamental algorithms for scientific computing in Python. Nature methods, 17(3), 261-272. 